\title{
Evaluation of a preventive educational program for malocclusions: 7-year study
}

\section{Beatriz Brandão SCARPELLI(a) Sandrine Bittencourt BERGER $R^{(b)}$ Marília Franco PUNHAGUI(a) Cássio Alexandre Zeri de OLIVEIRA(c) \\ Antonio FERELLE(a) \\ Paula Vanessa Pedron OLTRAMARI-NAVARRO(c)}

(a) Universidade Estadual de Londrina, Department Oral Medicine and Children's Dentistry, Londrina, PR, Brazil.

(b) Universidade do Norte do Paraná, Department of Restorative Dentistry, Londrina, PR, Brazil.

(c) Universidade do Norte do Paraná, Department of Orthodontics, Londrina, PR, Brazil.

Declaration of Interests: The authors certify that they have no commercial or associative interest that represents a conflict of interest in connection with the manuscript.

Corresponding Author:

Paula Vanessa Pedron Oltramari-Navarro

E-mail: pvoltramari@hotmail.com

DOI: 10.1590/1807-3107BOR-2016.vol30.0119

Submitted: Nov 19, 2015

Accepted for publication: Aug 16, 2016

Last revision: Aug 31, 2016
Abstract: This study aimed at evaluating the Protocol for the Prevention of Malocclusions (PPM), established in the preventive educational program developed by the Public Infant Oral Health Program of the State University of Londrina (PIOHP-UEL). Guardians of three-year-olds or older, maintaining nutritive (bottle) and/or non-nutritive (pacifier and finger) sucking habits, attended meetings designed to alert and guide them to eliminating these habits from their children. PPM patient records (2006-2013) were assessed and the data were described and evaluated by the Chi-square test, with a $5 \%$ significance level. Results: 506 of the 802 guardians/children referred to the PPM joined. As for the children, the most frequently assessed habits were: bottle (56.1\%), bottle and pacifier (18.4\%), finger $(11.9 \%)$, bottle and finger $(7.1 \%)$, pacifier $(5.7 \%)$, pacifier and finger $(0.6 \%)$, and bottle/pacifier/finger ( $0.2 \%)$. After parent participation in the meetings, $335(66.2 \%)$ children abandoned their habits. There was a statistical difference between type of oral habit and time to abandonment $(p=0.0001)$. However, those with only one habit abandoned it more easily $(72.6 \%)$ than those with two or more associated habits (48.1\%) $(p=0.042)$. Presence or absence of breastfeeding and parents' level of education had no significant effect on habit abandonment. Conclusion: PPM was an important tool for spreading knowledge to guardians, greatly contributing to the abandonment of deleterious oral habits. Bottle sucking warrants special attention - mentioned by $81.8 \%$ of parents - either alone or associated with other habits. Thus, educational actions to implement the children's approach to oral health are fundamental to making behavioral changes and promoting education of healthy habits, thereby keeping malocclusions from developing.

Keywords: Health Education; Habits; Malocclusion.

\section{Introduction}

The State University of Londrina develops a preventive educational program through its Public Infant Oral Health Program (PIOHP-UEL). This program targets children aged 0 to 6 years, and is both a national and international benchmark. This pioneering endeavor was begun in 1985, and has been kept up to the present day. It prioritizes oral health maintenance based on individual and collective care, focusing on a preventive educational approach. The service offers educational activities for parents, and conducts preventive actions for their children. According to 
Pinto et al. ${ }^{1}, 71.1 \%$ of the children from the PIOHP-UEL are free of caries, thus confirming the effectiveness of the oral health promotion program, which combines regular visits of the child for preventive treatment, together with the development of different parenting skills through educational activities.

Although the incidence of dental caries in the population served by the program has decreased significantly due to the actions taken, the prevalence of malocclusions in preschool children has become a matter of great interest to the PIOHP-UEL professional. According to a survey by the SB Brasil Project 2010², $69 \%$ of Brazilian children had at least one malocclusion at 5 years of age. Peres et al. ${ }^{3}$, carried out an oral health cohort study with 5,359 Brazilian children 6 years of age, and found that $61.1 \%$ had malocclusions. With this in mind, the Protocol for the Prevention of Malocclusions (PPM) was implemented as of October 2005 in the PIOHP-UEL as an educational activity. It brings together parents of three-year-old children and older, who participated in the PIOHP-UEL, but who maintained their nutritive (bottle) and/or non-nutritive (pacifier and finger) sucking habits. The meetings were designed to make guardians/children aware of the importance of removing these habits, to help find answers to questions on the association between habit and malocclusion, to create a support network where they could exchange experiences and leave the meeting stronger to deal with this difficult phase, and to contribute to introducing healthy practices and maintaining good oral health.

The program aims at assisting guardians in the difficult task of removing sucking habits from their children, thus preventing against malocclusion in the deciduous dentition, and minimizing the use and related costs of orthodontic appliances ${ }^{4}$. This study is important because it demonstrates the need to broaden actions dealing with malocclusions, and to implement prevention/interception programs in the initial period of orofacial development. Although a number of studies ${ }^{5-8}$ describe deleterious oral habits as important etiological factors in the development of malocclusions in deciduous and mixed dentures, according to Nihi et al. ${ }^{9}$, dentists must advise parents and guardians of the risks of prolonged indulgence in sucking habits and of the importance for children to receive preventive multidisciplinary care to minimize future risks.

The objective of this study was to evaluate the results of seven years of PPM implementation, in order to better understand the deleterious oral habits of this young population, and its association with other factors related to the development of malocclusions.

\section{Methodology}

TheHuman Ethics Committee of UNOPARapproved this study protocol (CAAE 18629213.8.0000.0108).

The sample for this cross-sectional study was obtained from the records of 7,343 children treated in the PIOHP-UEL, from 2006 to 2013. According to these records, 802 showed oral habits (nutritive and/or non-nutritive sucking habits) at 3 years old and older; for this reason, their guardians were invited to participate in the PPM. However, only 506 guardians joined the PPM to compose the study sample (Figure).

The Protocol for the Prevention of Malocclusions (PPM) was structured into four quarterly meetings (initial, 3-, 6- and 9 months) held with guardians and professionals to develop strategies to remove nutritive and non-nutritive oral habits from the children. The children of guardians who did not attend the PPM meetings were excluded from the PIOHP-UEL.

The methodology used to conduct the PPM meetings was the focus group approach (group dynamics) ${ }^{10,11}$, according to which 10 parents arranged themselves in a circle to talk informally for a period of 60 minutes. Participants were encouraged to report their doubts, experiences, difficulties and successes, in regard to removing nutritive and non-nutritive sucking habits. A pediatric dentist from the PIOHP-UEL led the meetings, and intervened at times to introduce information on the association between sucking habits and developing malocclusions. Guardians were also informed about the importance of early removal of deleterious oral habits, in order to minimize the development of malocclusions ${ }^{4}$, and thus reduce the need for specialized orthodontic treatment.

After each PPM meeting, regular appointments were scheduled in which children were assessed regarding caries prevention and oral habits. In these regular appointments, guardians were asked if their children abandoned the habit; otherwise, they received 


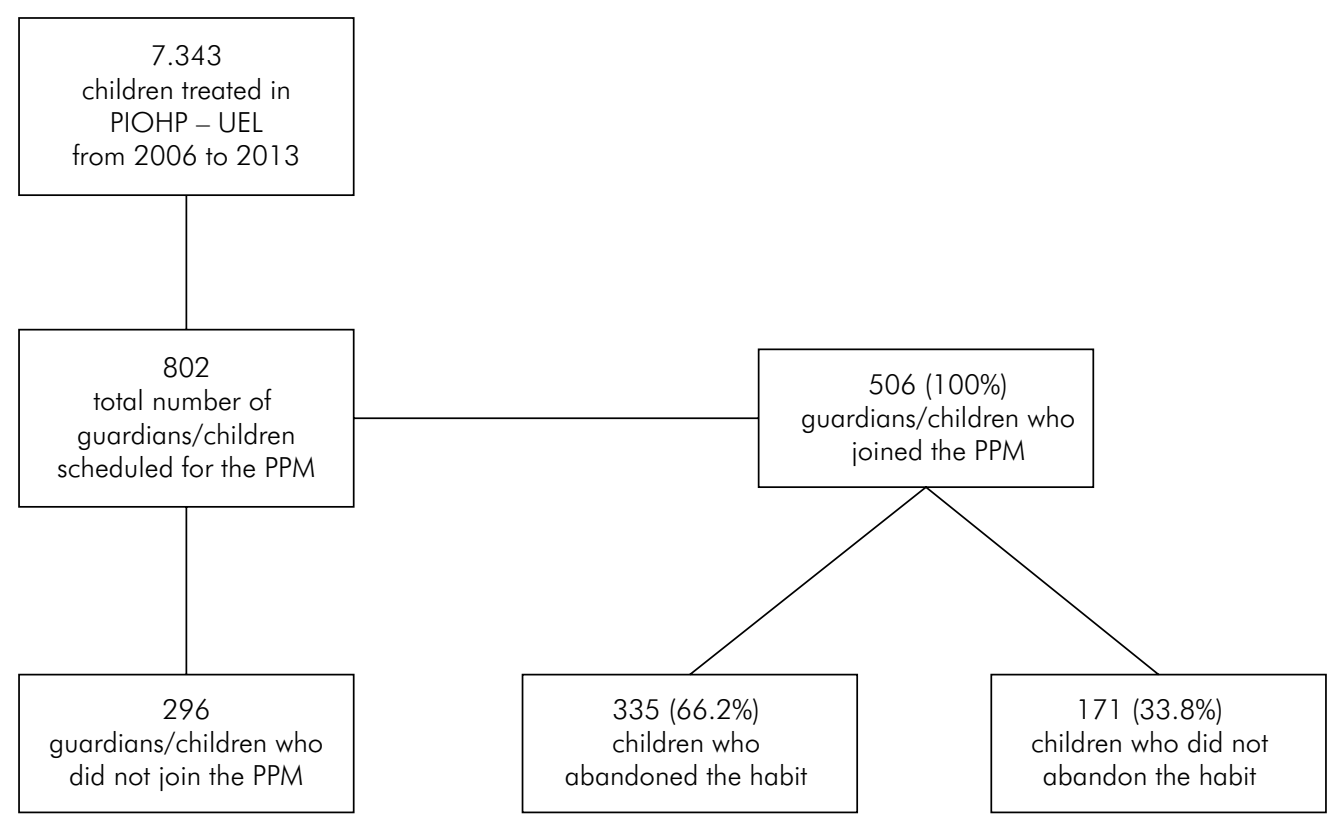

Figure. Organization chart.

individual counseling to reinforce the need for habit abandonment, insofar as individual counseling is an effective way of promoting behavioral changes in parents and improving oral health conditions in children ${ }^{12}$. Children's guardians, who did not report abandonment of the oral habit in a regular appointment, were invited to continue attending the PPM meetings. Once the children reported abandonment of the oral habit, they maintained only regular PIOHP-UEL appointments.

The results received statistical treatment according to the Statistical Package for Social Sciences (SPSS) Program, version 15.0, by descriptive analyses of the data, and applying the Chi square and the Fisher Freeman-Halton tests, with a level of significance of $5 \%$ and an interval of confidence of $95 \%$.

\section{Results}

In this study, $335(66.2 \%)$ children of the total sample $(\mathrm{n}=506)$ abandoned the oral habit (Figure); $54.1 \%$ were female and $45.9 \%$ were male, and their mean age was $3.7( \pm 0.7)$ years. The most commonly identified habit was bottle-feeding (56.1\%), followed by bottle and pacifier (18.4\%), finger (11.9\%), bottle and finger $(7.1 \%)$, pacifier $(5.7 \%)$, pacifier and finger $(0.6 \%)$, and bottle/pacifier/finger (0.2\%) (Table 1$)$.
Table 1. Characterization of the study sample - $n(\%)$.

\begin{tabular}{|c|c|c|c|}
\hline \multirow{2}{*}{ Type of habit } & \multicolumn{2}{|c|}{ Gender } & \multirow{2}{*}{ Total } \\
\hline & Female & Male & \\
\hline Bottle & $141(27.9)$ & $143(28.2)$ & $284(56.1)$ \\
\hline Bottle/pacifier & $49(9.7)$ & $44(8.7)$ & $93(18.4)$ \\
\hline Finger & $42(8.3)$ & $18(3.6)$ & $60(11.9)$ \\
\hline Bottle/finger & 20 (3.9) & $16(3.2)$ & $36(7.1)$ \\
\hline Pacifier & $193.7)$ & $10(2.0)$ & $29(5.7)$ \\
\hline Pacifier/finger & $3(0.6)$ & $0(0.0)$ & $3(0.6)$ \\
\hline Bottle/pacifier/finger & $0(0.0)$ & $1(0.2)$ & $1(0.2)$ \\
\hline Total & 274 (54.1) & 232 (45.9) & 506 (100.0) \\
\hline
\end{tabular}

The type of oral habit significantly influenced the decision to abandon it ( $p=0.0001$, Table 2). Furthermore, when the patient decided to abandon it, the finger habit alone (6 months) or this associated to the bottle habit ( 9 months) required more time to be abandoned.

Only $27.4 \%$ of children who had only one oral habit did not abandon it, compared with $51.9 \%$ of those with two or more associated habits. Of the children with only one type of habit, $46.6 \%$ succeeded 
in abandoning it in the first three months of the guardian's participation in the PPM. As for the children who had two or more habits, only $21.8 \%$ abandoned them in the first three months ( $p=0.042$, Table 3 ).

In the current study, no significant association was found between the abandonment of the sucking habit and breastfeeding history $(\mathrm{p}=0.283$, Table 4$)$. Of the total 506 children participating in the PPM, 421 showed a history of breastfeeding. Of these, $283(67.2 \%)$ were able to abandon the habit, and 52 $(61.2 \%)$ of the children with no breastfeeding history also succeeded.

Table 2. Distribution of the type of oral habits in relation to the time to abandonment.

\begin{tabular}{|c|c|c|c|c|c|}
\hline \multicolumn{6}{|c|}{ Abandonment of oral habits - $\mathrm{n}(\%)$} \\
\hline \multirow{3}{*}{ Type of habit* } & \multicolumn{3}{|c|}{ Yes } & \multirow{3}{*}{ No } & \multirow{3}{*}{ Total } \\
\hline & & to abandor & & & \\
\hline & 3 months & 6 months & 9 months & & \\
\hline \multirow{2}{*}{ Bottle } & & $235(82.7)$ & & \multirow{2}{*}{49 (17.3) } & \multirow{2}{*}{$284(100$} \\
\hline & $157(55.3)$ & $53(18.7)$ & $25(8.8)$ & & \\
\hline \multirow{2}{*}{ Bottle/pacifier } & & $49(52.7)$ & & & \\
\hline & $24(25.8)$ & $15(16.1)$ & $10(10.8)$ & $44(47.3)$ & $93(100)$ \\
\hline \multirow{2}{*}{ Finger } & & $12(20.0)$ & & & \\
\hline & $3(5.0)$ & $6(10.0)$ & $3(5.0)$ & $48(80.0)$ & $60(100)$ \\
\hline \multirow{2}{*}{ Bottle/finger } & & $235(38.9)$ & & & \\
\hline & $5(13.9)$ & $3(8.3)$ & $6(16.7)$ & $22(61.1)$ & $36(100)$ \\
\hline \multirow{2}{*}{ Pacifier } & & $24(82.8)$ & & & \\
\hline & $14(48.3)$ & $9(31.0)$ & $1(3.4)$ & $5(17.2)$ & $29(100)$ \\
\hline \multirow{2}{*}{ Pacifier/finger } & & $0(0.0)$ & & & \\
\hline & $0(0.0)$ & $0(0.0)$ & $0(0.0)$ & $3(100)$ & $3(100)$ \\
\hline \multirow{2}{*}{ Bottle/pacifier/finger } & & $1(100)$ & & & \\
\hline & $0(0.0)$ & $0(0.0)$ & $1(100)$ & $0(0.0)$ & $1(100)$ \\
\hline
\end{tabular}

*Statistically different. Fisher Freeman-Halton Test: 28.49. $p=0.0001$

Table 3. Distribution of the number of oral habits in relation to the abandonment of oral habits.

\begin{tabular}{|c|c|c|c|c|c|}
\hline \multicolumn{6}{|c|}{ Abandonment of oral habits [n (\%)] } \\
\hline \multirow{3}{*}{ Amount of oral habits* } & \multicolumn{3}{|c|}{ Yes } & \multirow{3}{*}{ No } & \multirow{3}{*}{ Total } \\
\hline & & to abandon & & & \\
\hline & 3 months & 6 months & 9 months & & \\
\hline \multirow{2}{*}{1 oral habit } & & $271(72.6)$ & & \multirow{2}{*}{$102(27.4)$} & \multirow{2}{*}{$373(100.0)$} \\
\hline & $174(46.6)$ & $68(18.3)$ & $29(7.8)$ & & \\
\hline \multirow{2}{*}{2 or more oral habits } & & $64(48.1)$ & & \multirow{2}{*}{$69(51.9)$} & \multirow{2}{*}{$133(100.0)$} \\
\hline & $29(21.8)$ & $18(13.5)$ & $17(12.8)$ & & \\
\hline Total & $203(40.1)$ & $86(17.0)$ & $46(9.1)$ & $171(33.9)$ & $506(100.0)$ \\
\hline
\end{tabular}

* Statistically different, Chi Square: $36.225, \mathrm{p}=0.042$. 
Additionally, no significant association was found between abandonment of the sucking habit and parental education ( $p=0.051$, Table 5). The highest rates of habit abandonment were found in children whose parents had an incomplete elementary education (75\%), followed by a complete college education (73.8\%), a complete elementary education (63.4\%) and a complete secondary education (60.3\%). It was also found that the highest habit abandonment rate (39.9\%) was found in the first three months after the PPM began. After six months and nine months, the rate was $17.1 \%$ and $9.1 \%$, respectively (Table 5).

Table 4. Distribution of the adoption of breastfeeding in relation to the abandonment of oral habits.

\begin{tabular}{lccc}
\hline \multicolumn{4}{c}{ Abandonment of oral habits [n (\%)] } \\
\hline Breastfeeeding & Yes & No & TOTAL \\
\hline Yes & $283(67.2)$ & $138(32.8)$ & $421(100)$ \\
No & $52(61.2)$ & $33(38.8)$ & $85(100)$ \\
Total & $335(66.2)$ & $171(33.8)$ & $506(100)$ \\
\hline
\end{tabular}

Chi Square: 1.155, $p=0.283$.

\section{Discussion}

Parental involvement in preventive educational programs is essential, since parents are co-responsible for the promotion and maintenance of the oral health conditions of their children, and have the role of pursuing a better quality of life $\mathrm{e}^{7,13}$. The knowledge acquired by parents and their children, invariably, has repercussions on the oral health practices of other family members ${ }^{14}$.

Even after the children received frequent guidance to abandon bottle, pacifier and finger habits, this study found that $802(10.9 \%)$ of the 7,343 assessed children treated in the PIOHP-UEL (2006-2013) retained nutritive and non-nutritive habits at 3 years of age (Figure). Garbin et al. ${ }^{13}$ reported that even knowing that pacifier sucking may damage oral health, most parents offer a pacifier to calm the child. The difficulty in abandoning sucking habits has been highlighted in the literature of other studies, which shows even more significant data in populations not assisted by specific programs, like the studies by Santos et al. ${ }^{15}$ and Moimaz et al. ${ }^{16}$. These authors verified that these habits were maintained in $40.2 \%$ and $53.3 \%$ of the children, respectively, thus drawing

Table 5. Distribution of the level of parental education in relation to abandonment time of oral habits.

\begin{tabular}{|c|c|c|c|c|c|}
\hline \multicolumn{6}{|c|}{ Abandonment of oral habits [n (\%)] } \\
\hline \multirow{3}{*}{ Level of parental education } & \multicolumn{3}{|c|}{ Yes } & \multirow{3}{*}{ No } & \multirow{3}{*}{ TOTAL } \\
\hline & & to abandon & & & \\
\hline & 3 months & 6 months & 9 months & & \\
\hline \multirow[b]{2}{*}{ Incomplete elementary education } & & $12(75.0)$ & & \multirow[b]{2}{*}{$4(25.0)$} & \multirow[b]{2}{*}{$16(100.0)$} \\
\hline & $7(43.8)$ & $4(25.0)$ & $1(6.3)$ & & \\
\hline \multirow[b]{2}{*}{ Complete elementary education } & & $45(63.4)$ & & \multirow[b]{2}{*}{$26(36.6)$} & \multirow[b]{2}{*}{$71(100.0)$} \\
\hline & $31(43.7)$ & $11(15.5)$ & $3(4.2)$ & & \\
\hline \multirow[b]{2}{*}{ Complete secondary education } & & $141(60.3)$ & & \multirow[b]{2}{*}{$93(39.7)$} & \multirow[b]{2}{*}{$234(100.0)$} \\
\hline & $85(36.3)$ & $33(14.2)$ & $23(9.8)$ & & \\
\hline \multirow[b]{2}{*}{ Complete college education } & & $137(73.8)$ & & \multirow[b]{2}{*}{$48(26.2)$} & \multirow[b]{2}{*}{$185(100.0)$} \\
\hline & $80(42.6)$ & $38(20.8)$ & $19(10.4)$ & & \\
\hline Total & $203(39,9)$ & $86(17.1)$ & $46(9.1)$ & $171(33.9)$ & $506(100.0)$ \\
\hline
\end{tabular}

Chi: $13.280, p=0.051$ 
attention to the problem of having no guidance program in place.

It is important to emphasize that the bottle sucking habit was the most prevalent oral habit, since it was mentioned by $81.8 \%$ of the guardians, either alone (56.1\%) or associated with other habits (bottle/pacifier: $18.4 \%$, bottle/finger: $7.1 \%$, bottle/pacifier/finger: 0.2 ) (Table 1). This high prevalence of the bottle sucking habit was also verified by Moimaz et al. ${ }^{17}(96.2 \%)$ and Massuia et al. ${ }^{4}(87.2 \%)$. Therefore, although the vast majority of parents report that the bottle habit can cause damage to their children's teeth, Garbin et al. ${ }^{13}$ revealed that they encountered a high degree of difficulty to remove it, because removal involves modification of eating habits and replacing the supply of milk. This same difficulty was pointed out by the guardians of children involved in this study, indicating that this reluctant behavior deserves special attention from dentists, who should instruct parents not to use bottles if possible, or at least remove this habit earlier ${ }^{9,18}$.

Moreover, the difficulty in abandoning sucking habits after 3 years of age may signal a psychological disorder related to the inability to deal with situations of emotional stress and anxiety, and a return to childish behavior. For this reason, it is expected that, at 3 years of age, the child is able to give up sucking habits ${ }^{15}$, thus reducing the risk of malocclusion ${ }^{19}$.

The current study demonstrated that the type of oral habit could significantly influence the habit-abandoning decision (Table 2). The bottle habit was the most prevalent and the easiest to be removed, given that $55.3 \%$ of the children with this habit were able to abandon it 3 months after the first PPM meeting. A similar result was verified for the pacifier habit, considering that $48.3 \%$ of the children also abandoned this habit 3 months after the first PPM meeting, though this habit was less prevalent in the studied population. On the other hand, more time was necessary to abandon the finger sucking habit. These data are significant, since Bishara et al. ${ }^{20}$ showed that if pacifier and finger sucking habits exceed 48 months of age, the induction potential of malocclusion increases considerably. Moreover, finger or pacifier sucking habits led to a higher prevalence of overjet ${ }^{17}$.

In addition, this study found that children who had only one habit abandoned it more easily (72.6\%)
(Table 3). These results concur with the studies by Massuia and Carvalho ${ }^{4}$, who found a significant association between the presence of malocclusions and sucking habits (bottle, pacifier and finger), and pointed out that the association of habits (bottle and finger) represents a greater difficulty for abandonment. Therefore, a deleterious habit is easier to eliminate when it is not associated with two or more habits.

In the present study, it was also found that 421 $(83.2 \%)$ of the 506 children surveyed were breastfed; this data shows that the recommendation by the World Health Organization ${ }^{21}$ is being observed. According to Santos et al. ${ }^{15}$ and Barreto ${ }^{22}$, breastfeeding should be encouraged, since it represents a mechanism of development and strengthening of facial muscles/bones, thereby contributing to the child's emotional maturity and to the prevention of sucking habits. However, no significant association was found in this study between abandoning the sucking habit and breastfeeding (Table 4). The data analyzed in this study are supported by the study by Hermont et al. ${ }^{23}$, which showed a lack of scientific evidence to confirm the association between the duration of breastfeeding and incidence of sucking habits and malocclusion. These authors also emphasize the importance of further cohort studies focusing exclusively on breastfeeding to elucidate this association.

Another relevant aspect refers to sucking habits as etiological factors for the development of malocclusions ${ }^{4,6,15,17}$. Dimberg et al. ${ }^{24}$ showed a significant association between sucking habits and anterior open bite and posterior crossbite. Corrêa-Faria et al. ${ }^{6}$ identified bottle feeding and deleterious oral habits as determinants for malocclusion in preschool children. Peres et al.7, found that $34 \%$ of the children studied showed greater horizontal overjet, $37 \%$ showed anterior open bite, and $10 \%$ showed posterior crossbite in the deciduous dentition. These studies reinforce the importance of encouraging early abandonment of sucking habits as a preventive measure for the development of malocclusions.

In addition, Santos et al. ${ }^{15}$ state that socioeconomic and educational factors could influence the oral health of children, and indicate an association between the parents' level of education and the occurrence of sucking habits $(p=0.006)$. However, Peres et al. ${ }^{7}$ found no association between maternal level of 
education and malocclusion. The association between the parents' level of education and the abandonment of the sucking habit was not significant in this study, considering that $39.9 \%$ of the children with the habit, who participated in the PPM, abandoned the habit in the first three months, regardless of their guardian's education level (Table 5). This is probably because all the parents in the PPM program received the same instructions, regardless of their socioeconomic level.

Because of the retrospective nature of this study, some important aspects such as dental occlusal, myofunctional performance and specific characteristics of oral habits (intensity, duration and frequency) were not included in the records and could not be assessed. Thus, prospective studies on oral habits should be encouraged, but the advantages of prospective trials must always be weighed on behalf of patient

\section{References}

1. Pinto LMCP, Walter LRF, Percinoto C, Dezan CC, Lopes MB. Dental caries experience in children attending an infant oral health program. Braz J Oral Sci. 2010;9(3):345-50.

2. Ministério da Saúde (BR), Secretaria de Atenção à Saúde, Secretaria de Vigilânica em Saúde, Coordenação Geral de Saúde Bucal. SB Brasil 2010: Pesquisa Nacional de Saúde Bucal: resultados principais. Brasília, DF: Ministério da Saúde; 2012.

3. Peres KG, Peres MA, Thomson WM, Broadbent J, Hallal PC, Menezes AB. Deciduous-dentition malocclusion predicts orthodontic treatment needs later: findings from a population-based birth cohort study. Am J Orthod Dentofacial Orthop. 2015;147(4):492-8. doi:10.1016/j.ajodo.2014.12.019

4. Massuia JM, Carvalho, WO. Prevalence and associated factors of malocclusion in the primary dentition. RGO - Rev Gaúcha Odontol. 2012;60(3):329-35.

5. Agarwal SS, Nehra K, Sharma M, Jayan B, Poonia A, Bhattal H. Association between breastfeeding duration, non-nutritive sucking habits and dental arch dimensions in deciduous dentition: a cross-sectional study. Prog Orthod. 2014; 15(1):59. doi:10.1186/s40510-014-0059-4

6. Corrêa-Faria P, Ramos-Jorge ML, Martins-Júnior PA, Vieira-Andrade RG, Marques LS. Malocclusion in preschool children: prevalence and determinant factors. Eur Arch Paediatr Dent. 2014;15(2):89-96. doi:10.1007/s40368-013-0069-9

7. Peres KG, Cascaes AM, Peres MA, Demarco FF, Santos IS, Matijasevich A et al. Exclusive breastfeeding and risk of dental malocclusion. Pediatrics. 2015;136(1):e60-7. doi:10.1542/peds.2014-3276 benefits, and investigations involving retrospective data should not be a depreciated option ${ }^{25}$.

Even though the parents were informed that sucking habits can damage their children's oral health, the prevalence of these habits in the population was high $^{6,13}$. Therefore, it is necessary to create projects that are aligned with the reality of the population, so that a continuous effort can be promoted to bring about changes in behavior and develop healthy habits.

\section{Conclusion}

The results of this study showed that the PPM-oriented preventive educational activity developed in the PIOHP-UEL constitutes an important instrument to spread knowledge to children's guardians, and has contributed greatly to the abandonment of deleterious oral habits.

8. Franco Varas V, Gorritxo Gil B. Pacifier sucking habit and associated dental changes: Importance of early diagnosis. An Pediatr (Barc). 2012;77(6):374-80. doi:10.1016/j.anpedi.2012.02.020

9. Nihi VS, Maciel SM, Jarrus ME, Nihi FM, Salles CL, Pascotto RC, et al. Pacifier-sucking habit duration and frequency on occlusal and myofunctional alterations in preschool children. Braz Oral Res. 2015;29(1):1-7. doi:10.1590/1807-3107BOR-2015.vol29.0013

10. Alves MU, Hass NA. Education buccal health: sensibilization of children's parents assisted in pediatric dentistry child clinic of two private universities. Pesq Bras Odontol Clin Integr. 2004;4(1):5.

11. Galvão AA, Colares V. Grupo de mães: uma proposta em odontopediatria. Arqu Odontol. 2004;40(4):9.

12. Harrison RL, Wong T. An oral health promotion program for an urban minority population of preschool children. Community Dent Oral Epidemiol. 2003;31(5):392-9. doi:10.1034/j.1600-0528.2003.00001.x

13. Garbin CA, Garbin AJ, Martins RJ, Souza NP, Moimaz SA. [Prevalence of non-nutritive sucking habits in preschoolers and parents' perception of its relationship with malocclusions]. Ciên Saude Colet. 2014;19(2):553-8. Portuguese. doi:10.1590/1413-81232014192.23212012

14. Barreto DM, Paiva SM, Ramos-Jorge ML, Ferreira MC. Evaluation of the effectiveness of an educational preventive activity with preschoolers: pilot study for a randomized clinical trial. Arq Odontol. 2013;49(3):113-2. doi:10.7308/aodontol/2013.49.3.02 
15. Santos SA, Holanda AL, Sena MF, Gondim LA,

Ferreira MA. Nonnutritive sucking habits among preschool-aged children. J Pediatr (Rio J). 2009;85(5):408-14. doi:10.2223/JPED.1926

16. Moimaz SA, Rocha NB, Garbin AJ, Saliba O. [The relation between maternal breast feeding and non-nutritive sucking habits]. Ciên Saúde Colet. 2011;16(5):2477-84. Portuguese. doi:10.1590/S1413-81232011000500017

17. Moimaz SA, Saliba O, Lolli LF, Garbin CA, Garbin AJ, Saliba NA. A longitudinal study of the association between breast-feeding and harmful oral habits. Pediatr Dent. 2012;34(2):117-21.

18. Fernandes IB, Pereira TS, de Carvalho MF, Ramos-Jorge J, Marques LS, Ramos-Jorge M. Non-nutritive sucking habits after three years of age: a case-control study. J Indian Soc Pedod Prev Dent. 2015;33(1):19-24. doi:10.4103/0970-4388.148965

19. Vasconcelos FM, Massoni AC, Heimer MV, Ferreira AM, Katz CR, Rosenblatt A. Non-nutritive sucking habits, anterior open bite and associated factors in Brazilian children aged 30-59 months. Braz Dent J. 2011;22(2):140-5. doi:10.1590/S0103-64402011000200009

20. Bishara SE, Warren JJ, Broffitt B, Levy SM. Changes in the prevalence of nonnutritive sucking patterns in the first 8 years of life. Am J Orthod Dentofacial Orthop. 2006;130(1):31-6. doi:10.1016/j.ajodo.2004.11.033

21. World Health Organization. Geneva: World Health Organization; 2011 [cited 2011 Jan 17]. Available from: http://www.who.int/en/.

22. Barreto LB, Souza RA, Freitas LM, Pithon MM. Association between breastfeeding and deleterious oral habits with development of malocclusions in pediatric dental patients. Int J Exp Dental Sci. 2012;1(2):61-6. doi:10.5005/jp-journals-1029-1016

23. Hermont AP, Martins CC, Zina LG, Auad SM, Paiva SM, Pordeus IA. Breastfeeding, bottle feeding practices and malocclusion in the primary dentition: a systematic review of cohort studies. Int J Environ Res Public Health. 2015;12(3):3133-51. doi:10.3390/ijerph120303133

24. Dimberg L, Lennartsson B, Söderfeldt B, Bondemark L. Malocclusions in children at 3 and 7 years of age: a longitudinal study. Eur J Orthod. 2013;35(1):131-7. doi:10.1093/ejo/cjr110

25. Viele K, Berry S, Neuenschwander B, Amzal B, Chen $\mathrm{F}$, Enas N, et al. Use of historical control data for assessing treatment effects in clinical trials. Pharm Stat. 2014;13(1):41-54. doi:10.1002/pst.1589 